\title{
ОСНОВНЫЕ КРИТЕРИИ ЭФФЕКТИВНОСТИ ФАНДРАЙЗИНГА В РОССИЙСКИХ НКо
}

\author{
(c) 2019 Басова Мария Михайловна \\ кандидат экономических наук, доцент Департамента учета, анализа и аудита \\ Финансовый университет при Правительстве Российской Федерации, Россия, Москва \\ E-mail: MMBasova@fa.ru
}

Статья посвящена анализу основных подходов к оценке эффективности фандрайзинговой деятельности НКО. Охарактеризованы основные критерии экономической и социальной эффективности фандрайзинга. Приведены рекомендации по повышению уровня эффективности с учетом интересов заинтересованных сторон, и в первую очередь доноров.

Ключевые слова: некоммерческие организации, фандрайзинг, фандрайзинговая деятельность, критерии эффективности, благотворительные организации, нефинансовая отчетность, административные расходы НКО.

Одной из основных функций управления некоммерческой организации (далее НКО) является фандрайзинг, который можно рассматривать, как сложный процесс по привлечению финансовых и нефинансовых ресурсов для своей деятельности. Фандрайзинг как функцию управления можно рассматривать как некую деятельность по привлечению денежных средств и иных ресурсов (материальных, человеческих, информационных и т.д.) из всех возможных каналов и источников финансирования на некоммерческие цели (реализацию определенного проекта или в целом своей деятельности), которые некоммерческая организация не может обеспечить самостоятельно.

В настоящее время в условиях конкуренции за «традиционные» ресурсы и в поисках новых каналов финансирования НКО должны постоянно оценивать эффективность своей фандрайзинговой работы. Анализ российских и зарубежных источников показал, что в практической деятельности организаций еще не сформулированы единые критерии оценки эффективности использования фандрайзинга. НКО в своей работе должны постоянно рассчитывать, оценивать и анализировать множество показателей количественного и качественного характера. По нашему мнению, критерии эффективности следует разделить на экономические и социальные.

Критерии эффективности фандрайзинговой деятельности определяются на основе расчета и анализа целой группы экономических и социальных показателей.

Обобщающими показателями экономиче- ской эффективности фандрайзинговой деятельности можно считать:

- «Чистый доход от фандрайзинга», определяемый как разность между общей суммой привлеченных средств и общей суммой затрат на фандрайзинг;

- «Эффективность фандрайзинга», которую можно определить, как соотношение полученного результата, выражаемого в общей сумме привлеченных средств, финансовых и нефинансовых ресурсов (разовые или регулярные платежи, целевые или нет и т.п.) к расходам на фандрайзинговую деятельность;

- «Эффективность благотворительных программ», определяемый отношением объема привлеченных средств на все программы (на отдельные программы) к общим расходам на все программы (на отдельные программы);

- «Индекс административных расходов Фонда», определяемый отношением расходов на содержание Фонда к общей сумме затрат на фандрайзинг.

Первые два показателя характеризуют уровень привлечения средств для реализации социальных программ, последние два - отражают целевое использование собранных средств. В зарубежной литературе аналогом этих показателей является показатель «Преданность благотворительности». Относительная величина этого показателя может быть рассчитана как отношение общей суммы поступивших средств из всех источников за определенный период времени к расходам на социальную и благотворительную помощь в целом и в разрезе отдельных 
программ разрезах. Считается, что чем меньше цифра, тем меньше преданности» [1].

Практика показывает, что нельзя судить об эффективности фандрайзинга только по этой группе показателей. НКО должны мыслить стратегически и стремиться к расчету и анализу и других показателей (таблица 1).

В практике деятельности НКО, как правило, в нефинансовой отчетности - эти показатели не приводятся и даже не даются исходные данные для их расчета. На наш взгляд, для доноров, как большой группе заинтересованных сторон, эта информация важна и должна быть в открытом доступе. Могут возразить, что эту информацию можно найти в отдельных исследованиях агентств. Но доноров в первую очередь интересует конкретный Фонд, от которого он получил заявку и информацию о нем он будет искать в первую очередь на сайте этого Фонда. В этой связи, на наш взгляд, в перспективе в открытом доступе для всех заинтересованных сторон должна быть представлена информация о структуре расходов, количестве обращений НКО с просьбой о поддержке, динамике роста числа благотворителей (доноров, спонсоров) и другая информация.

Общая группа показателей экономической эффективности фандрайзинговой деятельности Благотворительного фонда помощи детям с онкогематологическими и иными тяжелыми заболеваниями «ДоброСвет» (БФ «ДоброСвет») [2] представлена в таблицах 2 и 3.

Общая сумма средств, направленных на реализацию программ и проектов БФ «ДоброСвет» в 2018 году, составила 23235624,78 руб. Общий объем финансирования программ в 2018 году по сравнению с 2017 годом вырос на 6335038,53 рублей или 37,48\%. БФ «ДоброСвет» в 2018 году оказал помощь 109 благополучателям: 73 ребенка - г. Воронеж и 36 детей - Воронежская область.

Благотворительные программы Фонда реализуются на пожертвования частных лиц, компаний, ИП, акции «Белый цветок», государственные гранты и субсидии. Доходы Фонда в 2017 году составили - 16560426,15 рублей, а в 201827452761,65 рублей. Общие доходы БФ «ДоброСвет» в 2018 году по сравнению с 2017 годом выросли на 10892335,5 рублей или 65,77\%. Что может свидетельствовать об эффективной фан-

\section{Таблица 1. Количественные показатели экономической эффективности фандрайзинговой} деятельности некоммерческой организации

\begin{tabular}{|c|c|}
\hline Название коэффициента & Источник информации/Способ расчета \\
\hline $\begin{array}{l}\text { 1. Количество обращений НКО с предло- } \\
\text { жениями о поддержке }\end{array}$ & Данные рассчитываются на основе статистических данных НКО \\
\hline 2. Количество положительных ответов & Данные рассчитываются на основе статистических данных НКО \\
\hline $\begin{array}{l}\text { 3. Доля (\%) положительных ответов от } \\
\text { общего числа (процент отклика) }\end{array}$ & Рассчитывается как частное от деления стр. 2 на стр. 1 \\
\hline $\begin{array}{l}\text { 4. Средняя сумма полученной поддерж- } \\
\text { ки (средние взносы) за несколько лет }\end{array}$ & Рассчитывается по формуле средней арифметической \\
\hline $\begin{array}{l}\text { 5. Доход, полученный на единицу (сот- } \\
\text { ню) запросов }\end{array}$ & Рассчитывается как частное от деления стр.4 на стр. 1 \\
\hline $\begin{array}{l}\text { 6. Эффективность благотворительной } \\
\text { программы НКО }\end{array}$ & $\begin{array}{l}\text { Объем привлеченных средств на конкретную программу/ общие } \\
\text { расходы на данную программу }\end{array}$ \\
\hline $\begin{array}{l}\text { 7. Динамика роста объема пожертвова- } \\
\text { ний (за несколько лет) }\end{array}$ & $\begin{array}{l}\text { Эффективность измеряется простым сравнением результатов } \\
\text { текущего года с прошлогодним, или прошлогодними, на основе } \\
\text { расчета абсолютных, относительных и средних значений ряда } \\
\text { динамики }\end{array}$ \\
\hline $\begin{array}{l}\text { 8. Динамика роста числа благотворите- } \\
\text { лей (доноров, спонсоров) }\end{array}$ & $\begin{array}{l}\text { Эффективность измеряется простым сравнением результатов } \\
\text { текущего года с прошлогодним, или прошлогодними, на основе } \\
\text { расчета абсолютных, относительных и средних значений ряда } \\
\text { динамики }\end{array}$ \\
\hline $\begin{array}{l}\text { 9. Динамика привлечения новых благо- } \\
\text { творителей (доноров) }\end{array}$ & $\begin{array}{l}\text { Эффективность измеряется простым сравнением результатов } \\
\text { текущего года с прошлогодним, или прошлогодними, на основе } \\
\text { расчета абсолютных, относительных и средних значений ряда } \\
\text { динамики }\end{array}$ \\
\hline $\begin{array}{l}\text { 10. Индекс возвратности (постоянности) } \\
\text { донора }\end{array}$ & $\begin{array}{l}\text { Процент доноров от общего числа доноров на начало периода } \\
\text { (год), которые продолжают из года в год жертвовать НКО. Рассчи- } \\
\text { тывается на основе базы постоянных доноров }\end{array}$ \\
\hline
\end{tabular}


Таблица 2. Показатели экономической эффективности фандрайзинговой деятельности БФ «ДоброСвет»

\begin{tabular}{|c|c|c|c|c|c|c|c|c|}
\hline \multirow{2}{*}{ Показатели } & \multicolumn{2}{|c|}{2017} & \multicolumn{2}{|c|}{2018} & \multicolumn{2}{|c|}{$\begin{array}{c}\text { Абсолютное откло- } \\
\text { нение (+ -) }\end{array}$} & \multicolumn{2}{|c|}{ Темп прироста (\%) } \\
\hline & тыс. руб. & $\begin{array}{l}\text { Структу- } \\
\text { ра (\%) }\end{array}$ & тыс. руб. & $\begin{array}{l}\text { Структу- } \\
\text { ра (\%) }\end{array}$ & тыс. руб. & $\begin{array}{l}\text { Структу- } \\
\text { ра (\%) }\end{array}$ & $\%$ & $\begin{array}{l}\text { Структу- } \\
\text { ра (\%) }\end{array}$ \\
\hline \multicolumn{9}{|c|}{ Поступление средств } \\
\hline $\begin{array}{l}\text { Всего поступило } \\
\text { средств }\end{array}$ & 16560,43 & $100,00 \%$ & 27452,76 & $100,00 \%$ & 10892,34 & - & $65,77 \%$ & - \\
\hline В том числе: & & & & & 0,00 & & & \\
\hline От компаний & 3413,06 & $20,61 \%$ & 4811,61 & $17,53 \%$ & 1398,55 & $-3,08 \%$ & $40,98 \%$ & $-14,96 \%$ \\
\hline ИП & 1245,40 & $7,52 \%$ & 903,33 & $3,29 \%$ & $-342,07$ & $-4,23 \%$ & $-27,47 \%$ & $-56,25 \%$ \\
\hline Частных лиц & 7798,69 & $47,09 \%$ & 19905,34 & $72,51 \%$ & 12106,64 & $25,42 \%$ & $155,24 \%$ & $53,97 \%$ \\
\hline «Белый цветок» & 4103,27 & $24,78 \%$ & 600,00 & $2,19 \%$ & $-3503,27$ & $-22,59 \%$ & $-85,38 \%$ & $-91,18 \%$ \\
\hline Гранты и субсидии & & & 1232,48 & $4,49 \%$ & 1232,48 & $4,49 \%$ & & \\
\hline \multicolumn{9}{|c|}{ Израсходовано всего } \\
\hline $\begin{array}{l}\text { Всего израсходова- } \\
\text { но средств }\end{array}$ & 18046,99 & $100,00 \%$ & 24977,17 & $100,00 \%$ & 6930,18 & - & $38,40 \%$ & - \\
\hline \multicolumn{9}{|l|}{ В том числе: } \\
\hline По программам: & 16900,59 & $93,65 \%$ & 23235,62 & $93,03 \%$ & 6335,04 & $-0,62$ & $37,48 \%$ & $-0,66$ \\
\hline Помощь больнице & 6569,05 & $36,40 \%$ & 2738,64 & $10,96 \%$ & $-3830,41$ & $-25,44$ & $-58,31 \%$ & $-69,89$ \\
\hline Адресная помощь & 8309,81 & $46,05 \%$ & 16107,16 & $64,49 \%$ & 7797,34 & 18,44 & $93,83 \%$ & 40,05 \\
\hline Лекарства радости & 133,43 & $0,74 \%$ & 260,11 & $1,04 \%$ & 126,69 & 0,3 & $94,95 \%$ & 40,58 \\
\hline Дорогою добра & 735,63 & $4,08 \%$ & 1893,45 & $7,58 \%$ & 1157,82 & 3,5 & $157,39 \%$ & 85,86 \\
\hline Волонтерство & 329,17 & $1,82 \%$ & 465,58 & $1,86 \%$ & 136,41 & 0,04 & $41,44 \%$ & 2,19 \\
\hline Реабилитация & 823,49 & $4,56 \%$ & 1725,69 & $6,91 \%$ & 902,20 & 2,35 & $109,56 \%$ & 51,50 \\
\hline $\begin{array}{l}\text { Расходы на содер- } \\
\text { жание фонда }\end{array}$ & 1146,40 & $6,35 \%$ & 1741,54 & $6,97 \%$ & 595,14 & 0,62 & $51,91 \%$ & 9,76 \\
\hline
\end{tabular}

Таблица 3. Обобщающие показатели экономической эффективности фандрайзинговой деятельности БФ «ДоброСвет»

\begin{tabular}{|c|c|c|c|c|c|}
\hline Показатели & Способ расчета & 2017 год & 2018 год & $\begin{array}{l}\text { Абсолютное } \\
\text { отклонение }\end{array}$ & $\begin{array}{c}\text { Темп приро- } \\
\text { ста (\%) }\end{array}$ \\
\hline $\begin{array}{c}\text { 1. Чистый доход (убы- } \\
\text { ток) от фандрайзинга } \\
\text { (тыс. руб.) }\end{array}$ & $\begin{array}{c}\text { Общая сумма привле- } \\
\text { ченных средств - Об- } \\
\text { щая сумма затрат на } \\
\text { фандрайзинг }\end{array}$ & $-1486,5626$ & 2475,5942 & 3962,1568 & - \\
\hline $\begin{array}{c}\text { 2. Эффективность фан- } \\
\text { драйзинга (\%) }\end{array}$ & $\begin{array}{c}\text { Общая сумма привле- } \\
\text { ченных средств / Общая } \\
\text { сумма затрат на фан-- } \\
\text { драйзинг*100 }\end{array}$ & 91,76 & 109,91 & 18,15 & 19,78 \\
\hline $\begin{array}{c}\text { 3. Эффективность } \\
\text { благотворительных } \\
\text { программ (\%) }\end{array}$ & $\begin{array}{c}\text { Объем привлеченных } \\
\text { средств на программу/ } \\
\text { общие расходы на про- } \\
\text { граммы *100 }\end{array}$ & 97,99 & 118,15 & 20,16 & 20,58 \\
\hline $\begin{array}{c}\text { 4. Индекс администра- } \\
\text { тивных расходов Фонда } \\
(\%)\end{array}$ & $\begin{array}{c}\text { Расходы на содержание } \\
\text { фонда/ Общая сумма } \\
\text { затрат на фандрай- } \\
\text { зинг*100 }\end{array}$ & 6,35 & 6,97 & 0,62 & 9,76 \\
\hline
\end{tabular}


драйзинговой деятельности БФ «ДоброСвет».

Структура источников поступлений пожертвований на реализацию программы «Дорогою добра» приведена на рисунке 1 .

На рисунке 2 приводится динамика роста объема пожертвований, направляемых на реализацию программ и проектов Благотворительного фонда помощи детям с онкогематологическими и иными тяжелыми заболеваниями

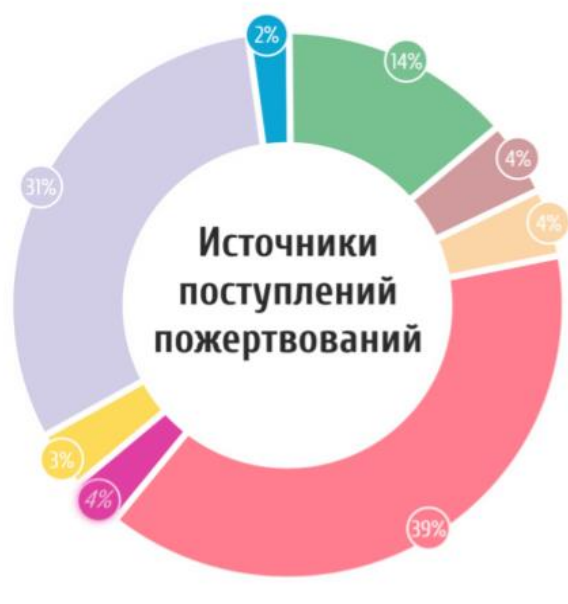

«ДоброСвет».

Анализ сайтов и публикаций российских НКО показал, что эффективность своей деятельности они в основном связывают с количеством реализованных программ, и конкретными данными и примерами в рамках оказанной помощи. Административные расходы часто становятся камнем преткновения в отношениях между НКО и донорами. Доноры при решении вопро-

- На реализацию и развитие программы «Дорогою добра» в 2018 г. направлено 1659720.63 р.

- Поступление пожертвований в течение года на постоянной основе стало возможным благодаря постоянному сотрудничествус юридическими и физическими лицами.

Рuc. 1. Структура источников поступлений пожертвований на реализацию программы «Дорогою добра» БФ «ДоброСвет»
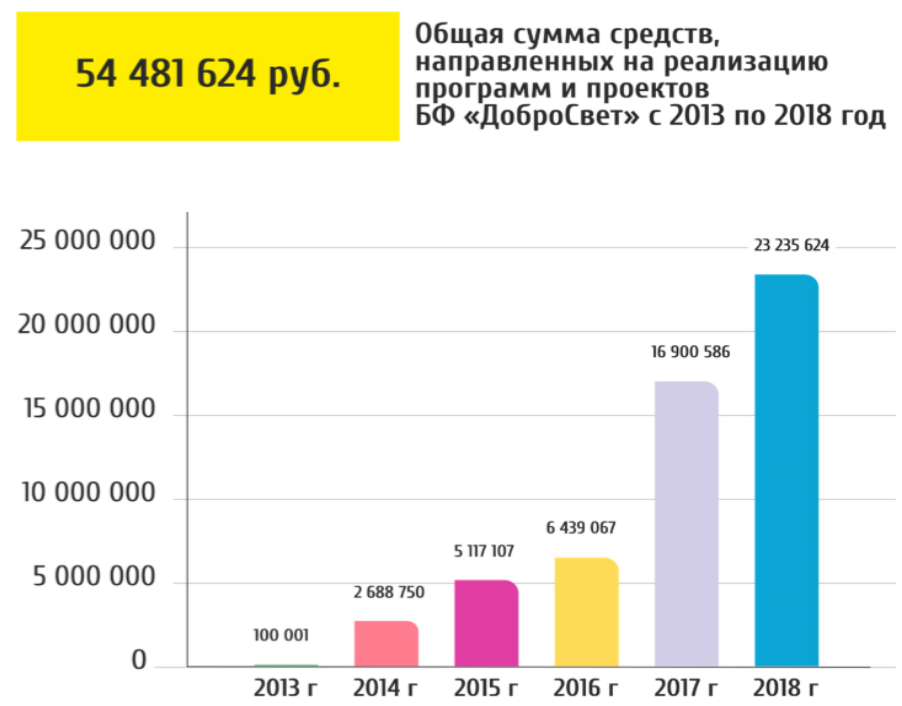

Puc. 2. Динамика роста объема пожертвований, направляемых на реализацию программ и проектов БФ «ДоброСвет» 
са о финансировании или не финансировании НКО, очень часто во главу угла ставят вопрос о структуре затрат: насколько низки у них их накладные расходы (какой процент от собранных средств уходит на них), каковы управленческие расходы. Отказ в финансировании в конечном итоге приводит к снижению уровня привлекаемых средств НКО, снижая тем самым эффективность фандрайзинговой деятельности.

Данные таблицы 3 свидетельствуют, что удельный вес расходов на содержание БФ «ДоброСвет» в 2018 году составил 6,97\%, а в 2017 году составлял 6,35\%. Таким образом, удельный вес расходов на содержание БФ «ДоброСвет» в 2018 году по сравнению с 2017 годом вырос на 0,62\%. Расходы на содержание БФ «ДоброСвет» включают расходы на оплату труда управления, развития и бухгалтерии; услуги банка; канцелярские товары; заправку картриджей; воду и т.п.

Не секрет, что многие компании, выделяющие деньги на различные благотворительные программы, всячески стремятся уменьшить, а зачастую и вообще исключить эту статью затрат. Однако во всем мире в коммерческом секторе на административные и иные «внутренние» нужды тратится значительно больше 10-20\% - нормы, которую до сих пор многие считают вполне достаточной для НКО. Распространенное в бизнесе отношение к административным расходам НКО как к «агентской комиссии» ограничивает возможности НКО для развития своих компетенций и материальной базы.

В этой связи актуальным остается вопрос: «Какой процент пожертвований должен идти на благотворительные программы, а какой на расходы Фонда?» Следует отметить, что единых законодательно установленных размеров затрат по данным статьям в российском правовом поле в настоящее время не выработано. Законодательством РФ (ФЗ № 135-ФЗ от 11.08.1995 «О Благотворительной деятельности благотворительных организаций») установлены следующие ограничения, касающиеся административных расходов НКО: «Благотворительная организация не вправе использовать на оплату труда административно-управленческого персонала более $20 \%$ финансовых средств, расходуемых этой организацией за финансовый год. Данное ограничение не распространяется на оплату труда лиц, участвующих в реализации благотворительных программ» [3]. Другими словами, речь идет о 20\% от суммы всех расходов НКО за год и только об оплате труда административно-управленческого персонала (директор, бухгалтер, отдел кадров, др.). Относительно размера административных расходов, а именно, доли затрат на содержание фонда в общей сумме трат НКО, надо отметить, что две трети фондов (66\%) вписываются в норматив, установленный государством для оплаты административно-управленческого персонала.

Проанализировав финансовые данные ряда российских НКО, можно прийти к выводу, что реальные затраты фондов на административные статьи в среднем превышают на $25 \%$ те суммы, которые согласны компенсировать частные и корпоративные доноры (в дальнейшем Доноры). Так, например, Межрегиональная общественная организация содействия программе воспитания подрастающего поколения «Старшие братья Старшие сестры» [4] в 2017 году направила на программную деятельность всего 47\% от полученных средств (в 2016 году это значение составляло 50\%); доля административнохозяйственных расходов, соответственно выросла. Обратная ситуация наблюдается в Фонде «Система» [5], где доля административно- хозяйственных расходов, включая и фандрайзинговые расходы, составила в 2016 году 11\%, а в 2017 году снизилась до 9\%. Это означает, что проекты реализовывались со значительным дефицитом необходимых человеческих, материальных и информационных ресурсов, что не могло не отразиться на результатах фандрайзинговой деятельности организации.

В развитых странах Северной Америки и Западной Европы административные расходы уже давно стали обязательной, легитимной и публичной частью финансового отчета НКО. Основанием этого подхода является устоявшееся мнение всех участников сектора (представителей фондов, доноров, партнерских и дружественных бизнес-структур, государства, СМИ, независимых экспертов и др.) о том, что успешная и эффективная некоммерческая организация не может обойтись без затрат на свое управление и содержание.

Весной 2016 года компания Deloitte опросила своих партнеров из числа социально-ориентированных некоммерческих организаций о том, какие существуют в этих организациях финансовые расходы, не приносящие непосредственную пользу подопечным этих организаций, а связаны с поддержанием функционирования 
самих организаций. На основе этого опроса был составлен отчет «Административные расходы НКО, или должны ли сотрудники фондов получать зарплату? [6] В отчете отмечалось, что большинство грантодающих фондов предоставляют основную часть финансовых средств на так называемую restricted program support - прямую поддержку программ, пытаясь всячески снизить и вводя ограничения на административные расходы фондов.

Значительная часть НКО не показывает административные расходы в своих отчетах и не всегда отчитываются публично, что не способствует росту доверия населения и доноров к их деятельности. Публичная отчетность российских НКО содержит много возможностей для улучшения данной ситуации: только у $49 \%$ действующих фандрайзинговых фондов, представленных в интернете (322 фонда), административные расходы указаны в отчетах на сайте Министерства юстиции, у 29\% есть такие расходы в отчетах на собственных сайтах [7].

В отличии от БФ «ДоброСвет», который указывают административные расходы в общих расходах, часть НКО закладывают административные расходы в программные (среди регио- нальных НКО так делают 40\% и 49\% «столичных» HKO).

Приведем пример. Православная служба помощи «Милосердие» - крупнейшая православная социальная служба России, которая помогает детям, старикам, больным и инвалидам, людям в беде, при составлении финансового отчета закладывает административные расходы в программные (рисунок 3).

В сложившейся ситуации, когда наблюдается, с одной стороны тесная связь между структурой затрат НКО и объемом финансирования, и с субъективным нежеланием отдельных доноров направлять свои ресурсы на благотворительные цели тем организациям, где по их мнению управленческие расходы достаточно высоки - с другой, на наш взгляд, необходимо разработать методические рекомендации по расчету оптимального соотношения структуры расходов для каждого сегмента НКО России, произвести необходимые расчеты с доказательной базой по оптимальности этих соотношений для доноров.

Говоря о критериях эффективности фандрайзинговой деятельности, нельзя забывать и о социальном эффекте. Оценка эффективности социальных программ, основывается, как пра-

Уход в больницах

\begin{tabular}{|l|r|}
\hline \multicolumn{1}{|c|}{ ПОСТУПЛЕНИЯ } & СУММА (тыс. руб.) \\
Пожертвования от юридических лиц & 6645 \\
Пожертвования от физических лиц & 668 \\
\multicolumn{1}{|c|}{ ИТОГО } & $\mathbf{7} 313$ \\
\hline \multicolumn{1}{|c|}{ ПЛАТЕЖИ } & СУММА (тыс. руб.) \\
Лекарства, медоборудование и медуслуги & 129 \\
Связь & 11 \\
Социальные расходы & 0 \\
Продукты питания & 3 \\
Коммунальные расходы & 3 \\
Технологические расходы (обслуживание компьютерного оборудования, \\
телефонии, приобретение и абонентское сопровождение ПО) \\
Транспортные расходы & 141 \\
Хозяйственные расходы & 31 \\
Общие расходы (комиссии банков, почтовые и нотариальные услуги) & 20 \\
Налоги & 35 \\
Зарплата сотрудников (включая налоги) & 23 \\
ИтОгО & 1 \\
\hline
\end{tabular}

Рис. 3. Финансовый отчет Православной службы помощи «Милосердие» по программе «Уход в больницах» за 2018 год 
Таблица 4. Оценка эффективности программы «Межрегиональная волонтерская программа наставничества для детей в трудной жизненной ситуации»

\begin{tabular}{|l|c|c|}
\hline \multirow{2}{*}{\multicolumn{1}{|c|}{ Показатели }} & \multicolumn{2}{c|}{2016 год } \\
\cline { 2 - 3 } & На начало года & На конец года \\
\hline Желание узнавать что-то новое & 4,5 & 7,8 \\
\hline Успешность в школьном обучении & 5,5 & 6,8 \\
\hline Умение логически мыслить & 4,7 & 6,6 \\
\hline Умение обращаться с деньгами & 4,6 & \\
\hline
\end{tabular}

вило, на методах социологических исследований. Приведем пример. Для оценки эффективности социальной программы «Межрегиональная волонтерская программа наставничества для детей в трудной жизненной ситуации», реализуемой в общественной организации содействия программе воспитания подрастающего поколения «Старшие братья Старшие сестры» [4], в 2016 году проводилось социологические исследования на основании анализа опросников, заполняемых наставниками программы. Опросник включал ряд показателей, которые оценивались по шкале от 1 до 10 баллов, где: 1-2 балла - ребенок практически не владеет данным навыком/качеством, 3-5 - ребенок владеет этим навыком/качеством частично, 6-8 - уровень развития данного навыка/качества достаточно высокий, 9-10 - peбенок практически полностью владеет данным навыком/качеством. Результаты были сведены в таблицу, фрагмент, которой представлен ниже (таблица 4).

Социальный результат деятельности фандрайзинговой кампании может быть оценен и на основе качественных показателей по следующим критериям: получены ли необходимые ресурсы, установлены ли взаимоотношения с волонтерами и потенциальными партнера- ми, привлечены ли спонсоры для организации специального мероприятия, создано ли информационное поле вокруг конкретного проекта.

Развитие некоммерческих организаций и благотворительности в целом невозможно без доверия к ним со стороны общества, властей, бизнеса и СМИ. Один из способов повысить доверие к себе - быть прозрачным - является составление нефинансовой отчетности, содержащей доступную, понятную, достаточную и актуальную информацию об организации, когда любое заинтересованное лицо может найти необходимые сведения и проанализировать их [8].

На основе этого, можно сделать следующее заключение: в целях развития фандрайзинговой деятельности и повышения ее эффективности, НКО должны расширить свою нефинансовую отчетность, включив в нее как административные расходы с указанием их структуры, а также всю необходимую информацию которая может заинтересовать доноров при принятии решения о выделении средств НКО. Расширение информационной базы НКО на собственном сайте, в СМИ и нефинансовой отчетности приведёт к повышению эффективности их фандрайзинговой деятельности.

\section{Библиографический список}

1. Петрова Т.Э. Общественные объединения и некоммерческие организации: деятельность и поддержка: монография / под ред. Т.Э. Петровой.-М.: ИНФРА-М, 2018.-118 с.

2. https://dobro-svet.ru

3. Федеральный закон от 11.08.1995 N135-Ф3 (ред. от 18.12.2018) «О благотворительной деятельности и добровольчестве (волонтерстве)», пункт 16.3

4. http://www.nastavniki.org/

5. http://bf.sistema.ru

6. https://takiedela.ru/wp-content/uploads/2017/03/2016_NP_Administrativnye-raskhody-NKO_Otchet-poissledovaniyu.pdf

7. https://www.miloserdie.ru/news/rossiyane-ne-hotyat-zhertvovat-na-administrativnye-nuzhdy-nko/

8. Басова М.М. Особенности составления нефинансовой отчетности в социально ориентированных некоммерческих организациях // Вестник Московского университета им. С.Ю. Витте. Серия 1: Экономика и управление. 2017. № 3 (22). С. 50-53. 
9. Возмилкина Е.Н. Фандрайзинг в социальной сфере // Научно-методический электронный журнал «Концепт».-2016. - Т. 11.- С. 4066-4070. [Электронный ресурс] - URL: http://e-koncept.ru/2016/86852.htm.

10. Корнеева И.Е. Фандрайзинг в российских некоммерческих организациях: результаты эмпирического исследования // Мониторинг общественного мнения: Экономические и социальные перемены. 2016 № 4 С. 48-66.

11. Официальный сайт Российского союза предпринимателей и промышленников [Электронный ресурс: http://media.rspp.ru] 